\title{
Risk factors for all-cause death after diagnosis of unruptured intracranial aneurysms
}

\author{
Juvela, Seppo
}

2015-02-03

Juvela , S \& Lehto , H 2015 , ' Risk factors for all-cause death after diagnosis of unruptured intracranial aneurysms ' , Neurology , vol. 84 , no. 5 , pp. 456-463 . https://doi.org/10.1212/WNL.0000000000001207

http://hdl.handle.net/10138/197741

https://doi.org/10.1212/WNL.0000000000001207

publishedVersion

Downloaded from Helda, University of Helsinki institutional repository.

This is an electronic reprint of the original article.

This reprint may differ from the original in pagination and typographic detail.

Please cite the original version. 


\section{Risk factors for all-cause death after diagnosis of unruptured intracranial aneurysms}

Seppo Juvela, MD, PhD Hanna Lehto, MD

Correspondence to Dr. Juvela: seppo.juvela@helsinki.fi

Editorial, page 442

Supplemental data at Neurology.org

\section{ABSTRACT}

Objectives: We investigated all-cause mortality and risk factors of death of patients with unruptured intracranial aneurysms (UIAs) in a long-term follow-up study.

Methods: A total of 142 patients with 181 UIAs diagnosed between 1956 and 1978 when UIAs were not treated were included in this study. Patients were followed until death or until 2011 to 2012. Mortality rates and risk factors were studied with Kaplan-Meier survival analysis and the Cox proportional hazards regression models.

Results: During 3,530 person-years, 113 (80\%) had died, giving an average annual mortality of $3.2 \%$. Of them, $19(17 \%)$ died of aneurysm rupture from the index UIA, 6 (5\%) of other aneurysm-related causes, and $2(2 \%)$ of unspecified subarachnoid hemorrhage. The remaining 86 died of causes unrelated to intracranial aneurysms. The cumulative death rate was $20 \%$ (95\% confidence interval $14 \%-27 \%)$ at 10 years and $60 \%(52 \%-68 \%)$ at 30 years. Independent risk factors for subsequent death were patient age (adjusted hazard ratio 1.09 per year, $95 \%$ confidence interval 1.05-1.12, $p<0.001)$, male sex $(2.81,1.59-4.96, p<0.001)$, heavy alcohol use $(4.22,2.22-8.02, p<0.001)$, and cigarette smoking $(1.72,0.97-3.07, p=0.064)$. History of hypertension, family history of subarachnoid hemorrhage, and diameter of UIA predicted death only in univariable analysis.

Conclusions: In patients of working age with a UIA, alcohol consumption and cigarette smoking are modifiable risk factors for untimely death through several causes and should be taken into account when treatment is considered. Neurology ${ }^{\circledR} 2015 ; 84: 456-463$

\section{GLOSSARY}

$\mathbf{B P}=$ blood pressure; $\mathbf{C I}=$ confidence interval; $\mathbf{H R}=$ hazard ratio; $\mathbf{S A H}=$ subarachnoid hemorrhage; $\mathbf{U I A}=$ unruptured intracranial aneurysm.

Saccular intracranial aneurysms develop during the lifetime in $3 \%$ of the population. ${ }^{1}$ Of these, approximately $25 \%$, or nowadays even less, ever rupture. ${ }^{2}$ Rupture of an aneurysm results in subarachnoid hemorrhage $(\mathrm{SAH})$ with a high case fatality rate. ${ }^{3-5}$

Those who survive 1 year after SAH seem to have almost 2-fold-higher mortality rate during subsequent decades as compared with the general population. ${ }^{5-7}$ This excess mortality is heterogeneous but is mostly attributable to vascular events including ischemic cerebrovascular stroke, poor outcome after $\mathrm{SAH}$, sequelae of $\mathrm{SAH}$, nonocclusion of ruptured aneurysms, or SAH from another aneurysm. ${ }^{5,7}$ Patients with untreated and even treated unruptured intracranial aneurysms (UIAs) seem also to have long-term excess mortality compared with the general population. ${ }^{8,9}$ This elevated mortality rate is likely attributable to both aneurysm ruptures and other cerebrovascular events. ${ }^{8,9}$

This elevated mortality rate of aneurysm patients mainly because of cerebrovascular diseases and subsequent new SAH episodes may be explained by the risk factors smoking, hypertension, and excessive alcohol drinking. ${ }^{10}$ UIAs, most of which (65\%-85\%) are $<7 \mathrm{~mm}$ in diameter, are now increasingly discovered. ${ }^{2,4}$ To estimate effectiveness of a preventive intervention, it is

From the Department of Clinical Neurosciences (S.J.), University of Helsinki; and Department of Neurosurgery (H.L.), Helsinki University Central Hospital, Finland.

Go to Neurology.org for full disclosures. Funding information and disclosures deemed relevant by the authors, if any, are provided at the end of the article. 
essential to know, in addition to the risk of aneurysm rupture, also the life expectancy and risk factors for the observed excess mortality.

Unruptured aneurysms were not operated on in Finland before $1979 .^{2}$ This long-term natural history study reports all-cause mortality and risk factors for death in patients of working age with UIAs covering almost the whole of their remaining life.

METHODS Patients. The series included 142 patients with UIAs diagnosed between 1956 and 1978 at the Department of Neurosurgery, Helsinki University Central Hospital, which was the only neurosurgical center in Finland until 1967 and remained responsible for neurosurgical services for $60 \%$ to $88 \%$ of the Finnish population between 1967 and $1978 .{ }^{2}$ For the detailed baseline characteristics of the 142 patients, see our previous reports. ${ }^{2,11,12}$ Most patients ( $\mathrm{n}=$ 131) were those with multiple aneurysms in whom only the ruptured one was clipped and occlusion was confirmed by postoperative angiography. Verification of the ruptured aneurysm was based on the signs of rupture in the surgical record. ${ }^{11}$ Additional evidence for the identification of ruptured aneurysm in these patients was as follows ${ }^{11}$ : the greater size of the ruptured aneurysm in 10 patients; the size with a secondary sac in 69 patients; intracerebral hematoma caused by the ruptured aneurysm in 38 patients; and oculomotor palsy associated with a ruptured internal carotid artery aneurysm in 14 patients. Patients with SAH and 2 or more aneurysms of equal size but without other evidence indicating which aneurysm had bled were treated conservatively and excluded from this study. Angiographies in the remaining 11 patients discovered either incidental ( $n=5$; chronic headache, nausea, dizziness, visual disorders) or symptomatic ( $\mathrm{n}=6$; cranial nerve deficits or cerebral infarction) UIAs. ${ }^{11}$

Follow-up methods. Follow-up evaluation was performed mainly by means of repeated postal questionnaires and telephone interviews obtained from patients and close relatives every 10 years from the 1960s onward. ${ }^{2,11-15}$ During the previous follow-up evaluations, the patients were interviewed (S.J.) by means of a structured questionnaire eliciting data on patient characteristics, previous diseases and hospital visits, use of medicines, and health habits. ${ }^{11-13}$ For the recording of blood pressure (BP) values, see our previous reports. ${ }^{11,13}$ Those who were alive between 1996 and 1998 were also interviewed in the outpatient clinic and a followup CT angiogram was performed. ${ }^{12} \mathrm{New}$ questionnaires were filled in between 2011 and 2012 based on telephone interviews either with patients or with relatives on demand. ${ }^{13}$ Alcohol consumption was recorded at the beginning of the follow-up in grams of absolute ethanol consumed within 1 week (standard drink $12 \mathrm{~g}$ of alcohol). Cigarette smoking was categorized as follows: never a smoker, formerly a regular cigarette smoker (quit before or during the follow-up), and current cigarette smoker. A family history of aneurysms was defined as $\geq 2$ verified ruptured aneurysm cases in first-degree relatives. ${ }^{2,13}$

Information on all the patients was also obtained from the medical records of other hospitals and general practitioners to confirm the accuracy of the data concerning diseases, medicines, and BP readings. ${ }^{11,13}$ UIAs without any rupture were occluded in 3 patients between 1997 and 1999 after follow-ups of 24.4 to 25.9 years. $^{2}$ Of 34 UIAs that ruptured during the follow-up, 16 were occluded after a rupture. Of these patients, 15 were conscious and one was in deep coma. ${ }^{16}$ Autopsy reports and official death certificates from the Causes of Death Register (Statistics Finland) were examined for all the deceased patients. In Finland, a statutory medicolegal autopsy is performed on all those who die due to trauma or unknown cause (Act on the Inquest into the Cause of Death, 459/1973, Finnish Law). The follow-up was complete.

Standard protocol approvals, registrations, and patient consents. All patients gave their written informed consent. The approval for the surveys and follow-up data collection has been obtained from the local ethics committee and in compliance with national legislation and the Declaration of Helsinki.

Statistical analysis. The data were analyzed with the IBM SPSS Statistics 22.0 for Windows (IBM Corp., Armonk, NY). Categorical variables were compared using Fisher exact 2-tailed test or the Pearson $\chi^{2}$ test, while the continuous variables were compared between groups using the Mann-Whitney $U$ test or $t$ tests.

For the life-table analysis and the Cox proportional hazards regression model, each patient was followed up until death or the last contact between 2011 and 2012. The average annual mortality was calculated by dividing the number of deaths by the number of person-years in the follow-up. Cumulative rates of death were estimated using the Kaplan-Meier product-limit method, and the curves for the groups were compared using the log-rank test.

Cox proportional hazards regression with a backward stepwise procedure (removal if $p>0.1$ ) and Wald statistics was used to determine hazard ratios (HRs) and 95\% confidence intervals (CIs) for several variables in predicting death. These variables, which were known at the beginning of the follow-up, were the following: age, sex, maximum aneurysm diameter, location of the largest UIA in each patient, presence of multiple UIAs, type of aneurysm (symptomatic or incidental vs those with prior SAH), cigarette-smoking status and current smoking, alcohol consumption, a family history of ruptured intracranial aneurysms, a history of hypertension (systolic BP $>140$ or diastolic BP $>90 \mathrm{~mm} \mathrm{Hg}$ or use of antihypertensive medication), and BP (systolic, diastolic, mean) values. Interactions between significant predictors of death were tested to see the extent to which they deviated from the additive effects of the main risk factors. The proportionality assumption was checked. The test of significance was based on changes in the $\log$ (partial) likelihood. A 2-tailed $p$ value $<0.05$ was considered statistically significant.

RESULTS Patient characteristics. Association of subsequent deaths with the baseline characteristics of the patient population is shown in table 1. Patient age $(p<0.05)$, approximate amount of alcohol consumed within 1 week $(p<0.05)$, and particularly heavy alcohol consumption $(p<0.01)$ were associated with subsequent death, as were male sex $(p=0.062)$ and smoking status $(p=0.086)$ but without reaching significance. Those who were active smokers the entire follow-up time had a higher death rate compared with others $(p=0.016)$, but current smokers at the beginning of follow-up had not because quitters accumulated among those who were alive at the end of follow-up. Men smoked more frequently both at the beginning ( $74 \%$ vs $42 \%, p<0.001)$ and at the end ( $60 \%$ vs $36 \%, p=0.01$ ) of follow-up, and they were also more frequently heavy alcohol drinkers (38\% vs $4 \%, p<0.001)$ than women. 
Table 1 Baseline characteristics of patients at the beginning of follow-up, grouped by subsequent death during follow-up

\begin{tabular}{|c|c|c|c|}
\hline Characteristic & Deceased $(n=113)$ & Alive $(n=29)$ & All patients $(n=142)$ \\
\hline Women, n (\%) & $56(50)$ & $20(69)$ & $76(54)$ \\
\hline Age, mean $\pm S D, y$ & $42.9 \pm 9.9^{a}$ & $37.6 \pm 9.6$ & $41.8 \pm 10.1$ \\
\hline Body mass index, mean $\pm \mathrm{SD}, \mathrm{kg} / \mathrm{m}^{2}$ & $25.8 \pm 3.8$ & $26.4 \pm 4.2$ & $25.9 \pm 3.9$ \\
\hline Blood pressure, mean $\pm \mathrm{SD}, \mathrm{mm} \mathrm{Hg}$ & $141 \pm 19 / 85 \pm 10$ & $135 \pm 15 / 85 \pm 9$ & $140 \pm 19 / 85 \pm 10$ \\
\hline History of hypertension, $\mathrm{n}(\%)$ & $43(38)$ & $8(28)$ & $51(36)$ \\
\hline \multicolumn{4}{|l|}{ Smoking status ( $n=123), n(\%)$} \\
\hline No & 27 (29) & $10(34)$ & $37(30)$ \\
\hline Quit before follow-up & $9(10)$ & $6(21)$ & $15(12)$ \\
\hline Quit during follow-up & $8(9)$ & $5(17)$ & $13(11)$ \\
\hline Current & $50(53)^{a}$ & $8(28)$ & $58(47)$ \\
\hline \multicolumn{4}{|l|}{ Alcohol consumption $(n=95)$} \\
\hline Median (range), g/wk & $70(0-1,000)^{a}$ & $2(0-350)$ & $20(0-1,000)$ \\
\hline $2300 \mathrm{~g} / \mathrm{wk}, \mathrm{n}(\%)$ & $19 / 66(29)^{b}$ & 1/29 (3) & $20 / 95(21)$ \\
\hline Family history of aneurysms $(n=94), n(\%)$ & $8(12)$ & $1(3)$ & $9(10)$ \\
\hline \multicolumn{4}{|l|}{ Diameter of largest aneurysm, $n$ (\%) } \\
\hline$\leq 6 \mathrm{~mm}$ & $92(81)$ & $24(83)$ & $116(82)$ \\
\hline$\geq 7 \mathrm{~mm}$ & $21(19)$ & $5(17)$ & $26(18)$ \\
\hline \multicolumn{4}{|l|}{ Location of largest aneurysm, $\mathrm{n}(\%)$} \\
\hline Internal carotid artery & 47 (42) & $13(45)$ & $60(42)$ \\
\hline Anterior cerebral artery & $5(4)$ & $1(3)$ & $6(4)$ \\
\hline Anterior communicating artery & $6(5)$ & $2(7)$ & $8(6)$ \\
\hline Middle cerebral artery & $52(46)$ & $12(41)$ & $64(45)$ \\
\hline Vertebrobasilar artery & 3 (3) & 1 (3) & 4 (3) \\
\hline Multiple unruptured aneurysms, $\mathrm{n}(\%)$ & $28(25)$ & $5(17)$ & $33(23)$ \\
\hline
\end{tabular}

History of hypertension was defined as systolic pressure repeatedly $>140 \mathrm{~mm} \mathrm{Hg}$ or diastolic pressure $>90 \mathrm{~mm} \mathrm{Hg}$, or as use of antihypertensive medication. Aneurysm size $=$ largest diameter in millimeters. Family history of aneurysms was defined as $\geq 2$ verified ruptured aneurysm cases in first-degree relatives.

${ }^{\mathrm{a}} \mathrm{p}<0.05$ and ${ }^{\mathrm{b}} \mathrm{p}<0.01$ for difference between groups.

At the beginning of follow-up, age by sex was similar (mean \pm SD age for men $42.2 \pm 9.2$ years vs for women $43.0 \pm 10.1$ years). At the end of follow-up, patient age was $66.6 \pm 13.4$ years (for men $62.5 \pm$ 12.4 years and for women $70.2 \pm 13.2$ years, $p<$ $0.001)$. Mean \pm SD age of 113 patients who had died was $64.0 \pm 13.1$ years (range 33.9-93.6 years; for men $60.2 \pm 11.6$ and for women $67.9 \pm 13.6$ years, $p<$ $0.01)$ and that of those who were alive was $77.0 \pm 8.6$ years (for men $77.0 \pm 5.7$ years and for women 76.9 \pm 9.8 years). Age at death was higher $(p<0.001)$ in those without SAH from UIA than in those with aneurysm rupture $(66.6 \pm 13.3$ vs $56.5 \pm 9.3$ years). Those who had died of unrelated causes $(65.9 \pm 13.2$ years; for men $61.0 \pm 11.8$ years and for women $71.5 \pm 12.6$ years, $p<0.001$ ) outlived those who died of SAH from UIA $(53.7 \pm 6.7$ years; for men $52.0 \pm 5.0$ years and for women $54.5 \pm 7.4$ years) by approximately 12 years $(p<0.001)$, even more in women (by 17 years).
Cumulative rates and causes of death. Annual and cumulative death rates according to baseline characteristics are shown in table 2. Patient age, male sex, cigarette smoking, and heavy alcohol consumption $(p<0.01)$ as well as hypertension $(p=0.052)$ and family history of ruptured aneurysms $(p=0.073)$ increased cumulative mortality. Survival curves of those with later SAH from UIA and those without are shown in figure e- 1 on the Neurology ${ }^{\circledR}$ Web site at Neurology.org. Curves did not differ significantly because not all patients with an aneurysm rupture die of SAH. However, mortality of those younger than 41 years was significantly higher if a UIA ruptured during the follow-up (figure e-2). Men, cigarette smokers, and heavy alcohol drinkers had higher mortality rates $(p<0.01)$ than others (figures e-3 to e-5). Prior SAH as well as the size, location, and multiplicity of UIAs did not predict subsequent death. 
Table 2 Annual and cumulative death rates, grouped by factors known at the beginning of follow-up

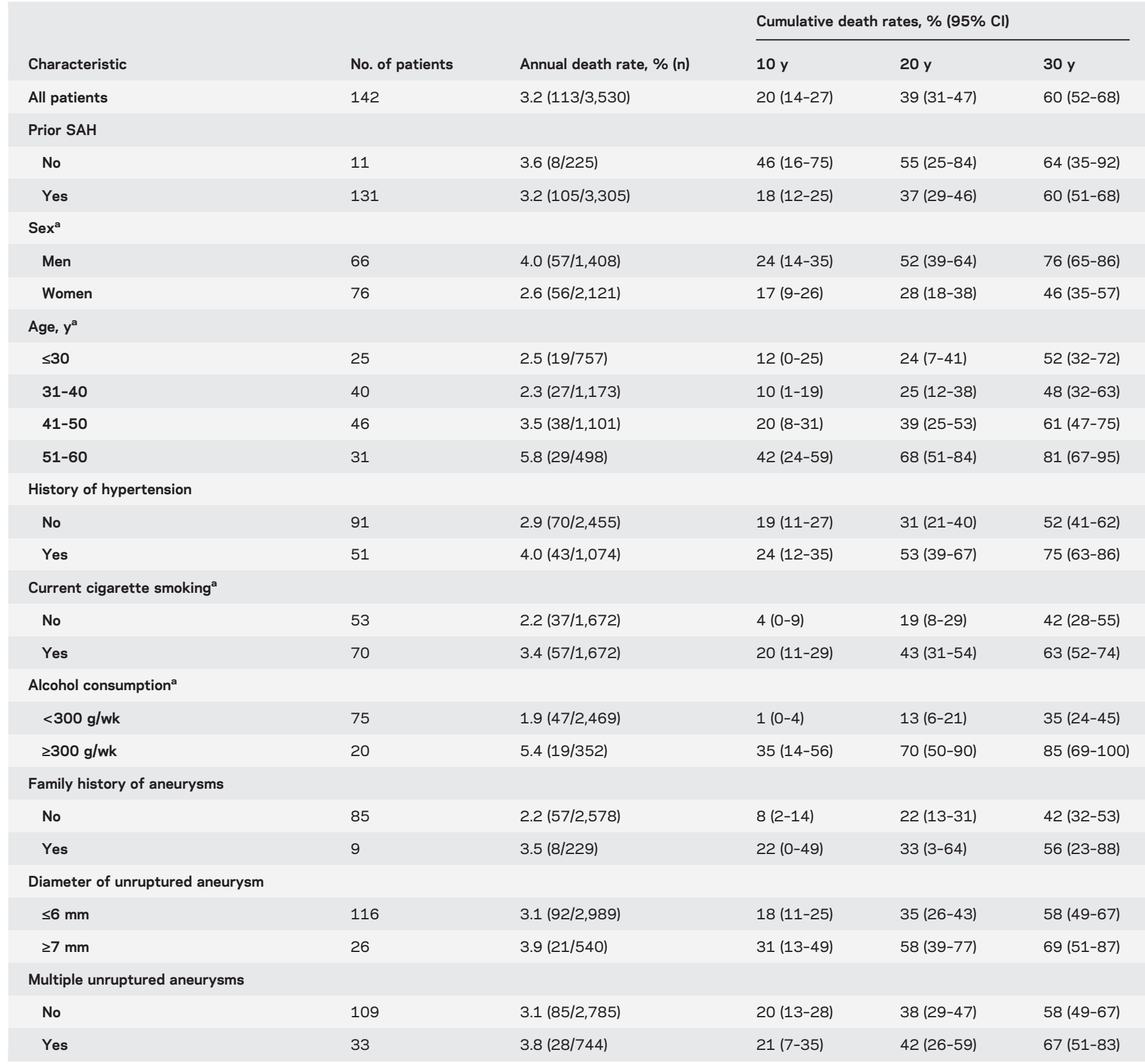

Abbreviations: $\mathrm{Cl}=$ confidence interval; $\mathrm{SAH}=$ subarachnoid hemorrhage.

Annual death rate is calculated by dividing the number of deceased patients by person-years of follow-up shown in parentheses.

${ }^{a} p<0.01$ for difference of cumulative mortality between groups (log-rank test).

The mean follow-up time per patient was 24.9 years (median 24.2, range $0.8-52.3$ years). Of the 142 patients, $113(80 \%)$ had died during the follow-up of 3,530 person-years, yielding an average annual mortality of $3.2 \%$. Of the 34 patients with SAH from previously diagnosed UIA, 18 patients died of either an aneurysm rupture or rerupture during a mean follow-up time of 11.4 years (range 1.424.2 years), and one of late rebleeding 2.9 years after aneurysm rupture with conservative treatment during a total follow-up of 20.1 years. Four patients died of $\mathrm{SAH}$ from a nonindex aneurysm (2 patients with verified de novo aneurysms and 2 with aneurysms diagnosed with follow-up CT angiograms but without having previous vertebral angiographies) during a mean follow-up of 28.5 years (range 13.4-51.0 years). Two patients aged 42.7 and 49.6 years died of typical SAH but without angiograms or autopsy 12.7 and 13.6 years after controlled occlusions of ruptured aneurysms, which were previously diagnosed index UIAs. One patient died of expansion of an unruptured giant aneurysm but without rupture and another patient aged 58.4 years died of SAH caused by fracture of aneurysm clip 24.0 years after 


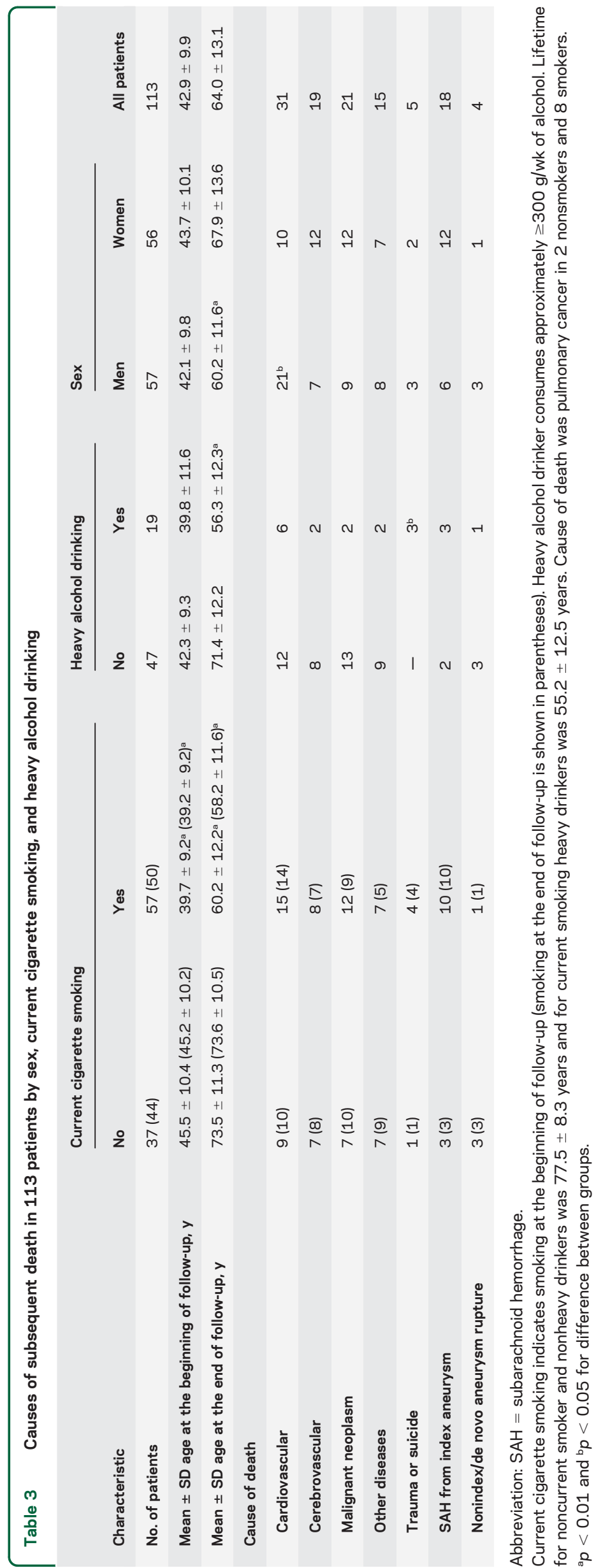

treatment of a ruptured aneurysm. The remaining 86 died of unrelated causes (31 of cardiovascular diseases, 14 of cerebrovascular diseases, 21 of malignant neoplasms, and 20 of other diseases or traumas).

Causes of death of 113 patients according to sex, cigarette smoking, and heavy alcohol consumption are shown in table 3. Men died of cardiovascular causes more frequently than women $(p=0.024)$ and heavy alcohol drinkers more frequently of trauma or suicide than others $(p=0.042)$. Furthermore, women died nonsignificantly more likely of $\mathrm{SAH}$, cerebrovascular diseases, and malignancies, smokers of SAH, and heavy drinkers of SAH and liver cirrhosis but less likely of malignancies, probably because they were relatively young at the time of death.

Other causes of untimely deaths were primary intracerebral hemorrhage (mean age 57.1, range 50.6-64.2 years), trauma or suicide $(46.1,33.9-$ 71.3 years), and hepatic cirrhosis (48.2, 40.7-55.6 years). However, those who died of SAH caused by de novo aneurysm or aneurysm verified during the follow-up were older (mean 70.5, range 63.4-80.2 years).

Risk factors for death. Univariable and multivariable HRs for the risk factors known at the beginning of the follow-up are shown in table 4. In univariable analysis, patient age (particularly older than 50 years), male sex, cigarette smoking, and heavy alcohol consumption were risk factors for death $(p<0.01)$. History of hypertension, family history of ruptured aneurysms, and diameter of UIA as a continuous variable did not reach significance. In multivariable analysis, age and male sex were independent risk factors for death. Current cigarette smoking at the beginning of follow-up also increased the risk for death (table 4; model I). When heavy alcohol consumption was included in the multivariable model, age, male sex, and heavy drinking were independent significant predictors of subsequent death (table 4; model II). Current cigarette smoking was not an independent predictor $(p=0.12)$ because it was closely correlated with the alcohol consumption $(p<$ 0.001). There were no significant interactions between the independent risk factors for death.

All those with missing data for either cigarette smoking or alcohol consumption were dead at the end of follow-up. If all patients with missing smoking status $(\mathrm{n}=19)$ are considered nonsmokers, current cigarette smokers at the beginning of follow-up still had almost significant increased risk of death after adjustment for age and sex (adjusted HR 1.45, $95 \%$ CI $0.97-2.16, p=0.068$ ). If those with missing alcohol status $(n=47)$ are considered also to be nondrinkers, heavy drinking was still a risk factor for death after adjustment for sex, age, cigarette 
Table $4 \quad$ Risk factors for all-cause death

\begin{tabular}{|c|c|c|c|c|}
\hline \multirow[b]{2}{*}{ Characteristic } & \multirow[b]{2}{*}{$\begin{array}{l}\text { No. of } \\
\text { patients }\end{array}$} & \multirow[b]{2}{*}{$\begin{array}{l}\text { Univariable HR } \\
\text { (95\% Cl) }\end{array}$} & \multicolumn{2}{|c|}{ Multivariable HR (95\% Cl) } \\
\hline & & & Model I & Model II \\
\hline \multicolumn{5}{|l|}{ Sex } \\
\hline Women & 76 & 1.00 & 1.00 & 1.00 \\
\hline Men & 66 & $1.74(1.19-2.53)^{a}$ & $2.32(1.30-4.17)^{\mathrm{a}}$ & $3.00(1.41-6.40)^{\mathrm{a}}$ \\
\hline \multicolumn{5}{|l|}{ Age, y } \\
\hline$<31$ & 25 & 1.00 & & \\
\hline $31-40$ & 40 & $0.98(0.54-1.79)$ & & \\
\hline $41-50$ & 46 & $1.71(0.96-3.03)$ & & \\
\hline$>50$ & 31 & $3.50(1.89-6.47)^{a}$ & & \\
\hline Continuous, per year & 142 & $1.05(1.03-1.07)^{a}$ & $1.07(1.03-1.10)^{\mathrm{a}}$ & $1.10(1.06-1.15)^{a}$ \\
\hline \multicolumn{5}{|l|}{ History of hypertension } \\
\hline No & 91 & 1.00 & & 1.00 \\
\hline Yes & 51 & $1.46(1.00-2.15)^{b}$ & $1.00(0.55-1.82)$ & $0.90(0.44-1.85)$ \\
\hline \multicolumn{5}{|l|}{ Current smoking } \\
\hline No & 53 & 1.00 & 1.00 & 1.00 \\
\hline Yes & 70 & $1.88(1.23-2.88)^{a}$ & $1.89(1.09-3.28)^{\mathrm{c}}$ & $1.67(0.88-3.19)$ \\
\hline \multicolumn{5}{|l|}{ Alcohol consumption } \\
\hline$<300 \mathrm{~g} / \mathrm{wk}$ & 75 & 1.00 & & 1.00 \\
\hline$\geq 300 \mathrm{~g} / \mathrm{wk}$ & 20 & $4.31(2.48-7.51)^{a}$ & & $3.98(1.68-9.43)^{\mathrm{a}}$ \\
\hline Alcohol consumption, per $100 \mathrm{~g} / \mathrm{wk}$ & 95 & $1.38(1.23-1.55)^{a}$ & & \\
\hline \multicolumn{5}{|l|}{ Family history of aneurysms } \\
\hline No & 85 & 1.00 & 1.00 & 1.00 \\
\hline Yes & 9 & $1.96(0.93-4.16)^{d}$ & $1.12(0.48-2.57)$ & $1.42(0.56-3.63)$ \\
\hline \multicolumn{5}{|l|}{ Diameter of unruptured aneurysm } \\
\hline$\leq 6 \mathrm{~mm}$ & 116 & 1.00 & & \\
\hline$\geq 7 \mathrm{~mm}$ & 26 & $1.36(0.85-2.19)$ & & \\
\hline Continuous, per mm & 142 & $1.06(0.99-1.12)^{d}$ & $0.99(0.87-1.12)$ & $0.84(0.70-1.02)$ \\
\hline
\end{tabular}

Abbreviations: $\mathrm{Cl}=$ confidence interval; $\mathrm{HR}=$ hazard ratio.

In multivariable analyses, the HRs were adjusted for the other variables listed in the table.

$a_{p}<0.01$.

${ }^{b} p=0.053$.

${ }^{c} p<0.05$

${ }^{d} p=0.08$.

smoking, hypertension, and aneurysm diameter (2.09, 1.22-3.58, $p=0.008)$.

DISCUSSION The patient's age, male sex, heavy alcohol consumption, and cigarette smoking seem, from the present results, to be independent risk factors for death among patients of working age with UIAs. Nonsmokers and nondrinkers outlived current smokers and heavy drinkers by approximately 10 to 20 years. History of hypertension or family history of ruptured aneurysms and size of aneurysm had only trend in univariable analysis for increased mortality.

Survivors 1 year after SAH as well as those with both untreated and possibly also treated UIAs seem to have higher mortality during subsequent decades as compared with the general population..$^{5-9}$ This excess mortality is attributable to both aneurysmrelated and -unrelated causes. Our study demonstrated that the ruptures from untreated UIAs accounted for $17 \%$ of all deaths and intracranial aneurysms including also ruptures from nonindex aneurysms (e.g., de novo aneurysms) and their sequelae for $24 \%$. Distribution of aneurysm-unrelated causes of death was similar to general Western populations. Mortality caused by a rupture of a diagnosed untreated UIA seems to be important because SAH causes only $0.6 \%$ of all deaths in Finland (approximately $300 \mathrm{SAH}$ deaths/50,000 all annual deaths; 
Statistics Finland). This is also supported by our previous observation of the lifelong rupture risk of $30 \%$ irrespective of aneurysm size among patients younger than 50 years. $^{2,17}$

Apart from being indisputable modifiable risk factors for $\mathrm{SAH},{ }^{10}$ cigarette smoking and heavy alcohol drinking seem to be main risk factors for all-cause mortality of patients with UIA, even much more important than aneurysm-associated factors. After inclusion of deceased patients with missing values for alcohol and smoking variables as nonsmokers and nondrinkers in models, smoking and heavy drinking were still important risk factors for death. These habits were also clearly more common in men than in women. However, this only partly explained the higher mortality rate in men because adjustment by these factors did not abolish the significant difference of mortality rates between men and women. Cardiovascular deaths seemed to account for the excess mortality among men. Although hypertension is the main risk factor for cardiovascular diseases, it unexpectedly did not predict independently the risk for subsequent mortality likely because of several reasons: (1) BP values correlated with age, (2) BP values were recorded at the beginning of follow-up and likely varied during the very long-lasting follow-up, (3) the patient population was relatively young and hypertension may be more important in older patients, and (4) all patients already had aneurysms, which are known to be associated with increased prevalence of hypertension.

Cigarette smoking and excess alcohol consumption increase premature death rate through several causes, e.g., cardiovascular and cerebrovascular events, some malignant neoplasms, liver cirrhosis, and trauma. ${ }^{18-20}$ Alcohol consumption is an important contributor to mortality and potential years of life lost, particularly in Europe. The average life expectancy of heavy alcohol drinkers is clearly lower than that of cigarette smokers because mortality caused by alcohol consumption occurs primarily among people of working age (approximately $5 \%$ of all deaths in people younger than 60 years). ${ }^{18-20}$ Compared with other risk factors (cigarette smoking, cholesterol, or hypertension), the alcohol-attributable disease burden is more important in younger people. ${ }^{19}$ The life expectancy is considerably shorter for men than for women. Much of the difference can be explained by cigarette smoking and harmful alcohol drinking. ${ }^{21}$

The strength of our cohort study is its unique nature with enrollment of patients of working age during the time when UIAs were not treated and the long-term follow-up covered the remainder of the patient's life in the majority of cases $(80 \%))^{2,22}$ There were also only few surgical withdrawals after a long-term follow-up ( $>24$ years), and the follow-up of our patients was complete.
A limitation of our study was that the patients were younger than in the other studies with UIA patients and mostly had multiple aneurysms, with the ruptured aneurysm clipped at the start of the follow-up. However, patients with either a history of SAH or multiple UIAs have not been shown to have a higher risk of aneurysm rupture than others when confounding factors are considered. ${ }^{2,22-24}$ Finnish people have also been considered to be subject to a higher risk of aneurysm rupture. ${ }^{22}$ However, there were 32 Finns enrolled in the International Study of Unruptured Intracranial Aneurysms during the $1990 \mathrm{~s},{ }^{22,23}$ but none of them had an aneurysm rupture within more than 200 follow-up years. This suggests that risk factors themselves are much more important than nationality considering aneurysm rupture risk. In the present study, missing values for alcohol consumption and cigarette smoking did not change the results after considering these in additional analyses.

When assessing treatment for UIAs, not only should aneurysm-related risk factors (aneurysm size and location) be considered but also life expectancy and the risk factors that shorten the lifespan. The younger the patient and the larger the aneurysm, the higher the indications for treatment become. ${ }^{2,4}$ However, the indication and benefit for treatment of UIAs in heavy drinkers may be quite questionable when the risks associated with heavy drinking are compared with those of the UIA. However, the indication for UIA treatment seems to be relatively high in smoking women because they also have a higher lifelong UIA rupture risk. ${ }^{17}$ While smoking shortens life expectancy, it increases risk of UIA rupture, and women outlive men. Irrespective of treatment indications, cessation of smoking and excess alcohol drinking and treatment of hypertension are, however, important for all aneurysm patients.

\section{AUTHOR CONTRIBUTIONS}

S.J. was responsible for the study design and data interpretation. S.J. was responsible for data analysis. S.J. and H.L. collected the data. S.J. drafted the report, and both authors critically revised the manuscript.

\section{ACKNOWLEDGMENT}

The authors thank Dr. Matti Porras for the analysis and measurement of aneurysm sizes in the initial angiograms.

\section{STUDY FUNDING}

This work was supported in part by research grants to Dr. Juvela from the Maire Taponen Foundation and the Paulo Foundation.

\section{DISCLOSURE}

S. Juvela serves as an associate editor for the European Journal of Neurology and on the editorial board of Stroke. H. Lehto reports no disclosures relevant to the manuscript. Go to Neurology.org for full disclosures.

Received April 16, 2014. Accepted in final form August 28, 2014. 


\section{REFERENCES}

1. Vlak MHM, Algra A, Brandenburg R, Rinkel GJE. Prevalence of unruptured intracranial aneurysms, with emphasis on sex, age, co-morbidity, country, and time period: a systematic review and meta-analysis. Lancet Neurol 2011;10: 626-636.

2. Juvela S, Poussa K, Lehto H, Porras M. Natural history of unruptured intracranial aneurysms: a long-term follow-up study. Stroke 2013;44:2414-2421.

3. Nieuwkamp DJ, Setz LE, Algra A, Linn FHH, de Rooij NK, Rinkel GJE. Changes in case fatality of aneurysmal subarachnoid haemorrhage over time, according to age, sex, and region: a meta-analysis. Lancet Neurol 2009; 8:635-642.

4. Steiner T, Juvela S, Unterberg A, Jung C, Forsting M, Rinkel G. European Stroke Organisation guidelines for the management of intracranial aneurysms and subarachnoid haemorrhage. Cerebrovasc Dis 2013;35:93-112.

5. Korja M, Silventoinen K, Laatikainen T, Jousilahti $P$, Salomaa V, Kaprio J. Cause-specific mortality of 1-year survivors of subarachnoid hemorrhage. Neurology 2013; 80:481-486.

6. Wermer MJ, Greebe P, Algra A, Rinkel GJ. Long-term mortality and vascular event risk after aneurysmal subarachnoid haemorrhage. J Neurol Neurosurg Psychiatry 2009;80:1399-1401.

7. Huttunen T, von und Zu Fraunberg M, Koivisto T, et al. Long-term excess mortality of 244 familial and 1502 sporadic one-year survivors of aneurysmal subarachnoid hemorrhage compared with a matched Eastern Finnish catchment population. Neurosurgery 2011;68:20-27.

8. Britz GW, Salem L, Newell DW, Eskridge J, Flum DR. Impact of surgical clipping on survival in unruptured and ruptured cerebral aneurysms: a population-based study. Stroke 2004;35:1399-1403.

9. Pyysalo L, Luostarinen T, Keski-Nisula L, Öhman J. Long-term excess mortality of patients with treated and untreated unruptured intracranial aneurysms. J Neurol Neurosurg Psychiatry 2013;84:888-892.

10. Feigin VL, Rinkel GJ, Lawes CM, et al. Risk factors for subarachnoid hemorrhage: an updated systematic review of epidemiological studies. Stroke 2005;36:2773-2780.

11. Juvela S, Porras M, Heiskanen O. Natural history of unruptured intracranial aneurysms: a long-term follow-up study. J Neurosurg 1993;79:174-182.
12. Juvela S, Poussa K, Porras M. Factors affecting formation and growth of intracranial aneurysms: a long-term followup study. Stroke 2001;32:485-491.

13. Juvela S, Porras M, Poussa K. Natural history of unruptured intracranial aneurysms: probability of and risk factors for aneurysm rupture. J Neurosurg 2000;93:379-387.

14. Heiskanen O, Marttila I. Risk of rupture of second aneurysm in patients with multiple aneurysms. J Neurosurg 1970;32:295-299.

15. Heiskanen O. Risk of bleeding from unruptured aneurysm in cases with multiple intracranial aneurysms. J Neurosurg 1981;55:524-526.

16. Juvela S. Prehemorrhage risk factors for fatal intracranial aneurysm rupture. Stroke 2003;34:1852-1857.

17. Korja M, Lehto H, Juvela S. Lifelong rupture risk of intracranial aneurysms depends on risk factors: a prospective Finnish cohort study. Stroke 2014;45:1958-1963.

18. Rossow I, Amundsen A. Alcohol abuse and mortality: a 40-year prospective study of Norwegian conscripts. Soc Sci Med 1997;44:261-267.

19. Rehm J, Mathers C, Popova S, Thavorncharoensap M, Teerawattananon Y, Patra J. Global burden of disease and injury and economic cost attributable to alcohol use and alcohol-use disorders. Lancet 2009;373: 2223-2233.

20. Shield KD, Taylor B, Kehoe T, Patra J, Rehm J. Mortality and potential years of life lost attributable to alcohol consumption in Canada in 2005. BMC Public Health 2012; 12:91.

21. Murray CJ, Lopez AD. Global mortality, disability, and the contribution of risk factors: Global Burden of Disease Study. Lancet 1997;349:1436-1442.

22. Greving JP, Wermer MJH, Brown RD Jr, et al. Development of the PHASES score for prediction of risk of rupture of intracranial aneurysms: a pooled analysis of six prospective cohort studies. Lancet Neurol 2014;13: 59-66.

23. Wiebers DO, Whisnant JP, Huston J III, et al; International Study of Unruptured Intracranial Aneurysms Investigators. Unruptured intracranial aneurysms: natural history, clinical outcome, and risks of surgical and endovascular treatment. Lancet 2003;362:103-110.

24. Morita A, Kirino T, Hashi K, et al. The natural course of unruptured cerebral aneurysms in a Japanese cohort. N Engl J Med 2012;366:2474-2482.

\section{Subspecialty Alerts by E-mail!}

Customize your online journal experience by signing up for e-mail alerts related to your subspecialty or area of interest. Access this free service by visiting Neurology.org/site/subscriptions/etoc.xhtml or click on the "E-mail Alerts" link on the home page. An extensive list of subspecialties, methods, and study design choices will be available for you to choose from—allowing you priority alerts to cutting-edge research in your field! 
NEUROLOGY 2014/590349: Risk Factors for All-cause Death after Diagnosis of Unruptured Intracranial Aneurysms

Seppo Juvela and Hanna Lehto

Supplemental figure e-1: Cumulative survival curves of those with and without a later subarachnoid hemorrhage from diagnosed unruptured aneurysm.

Supplemental figure e-2: Cumulative survival curves of those with and without a later subarachnoid hemorrhage from diagnosed unruptured aneurysm according to age groups ( $<41$ years vs. vs. vs. $\geq 41$ years).

Supplemental figure e-3: Cumulative mortality in relation to sex.

Supplemental figure e-4: Cumulative survival in relation to cigarette smoking.

Supplemental figure e-5: Cumulative survival in relation to heavy alcohol consumption. 
Figure e-1. Cumulative survival curves of those with and without a later subarachnoid hemorrhage from diagnosed unruptured aneurysm.

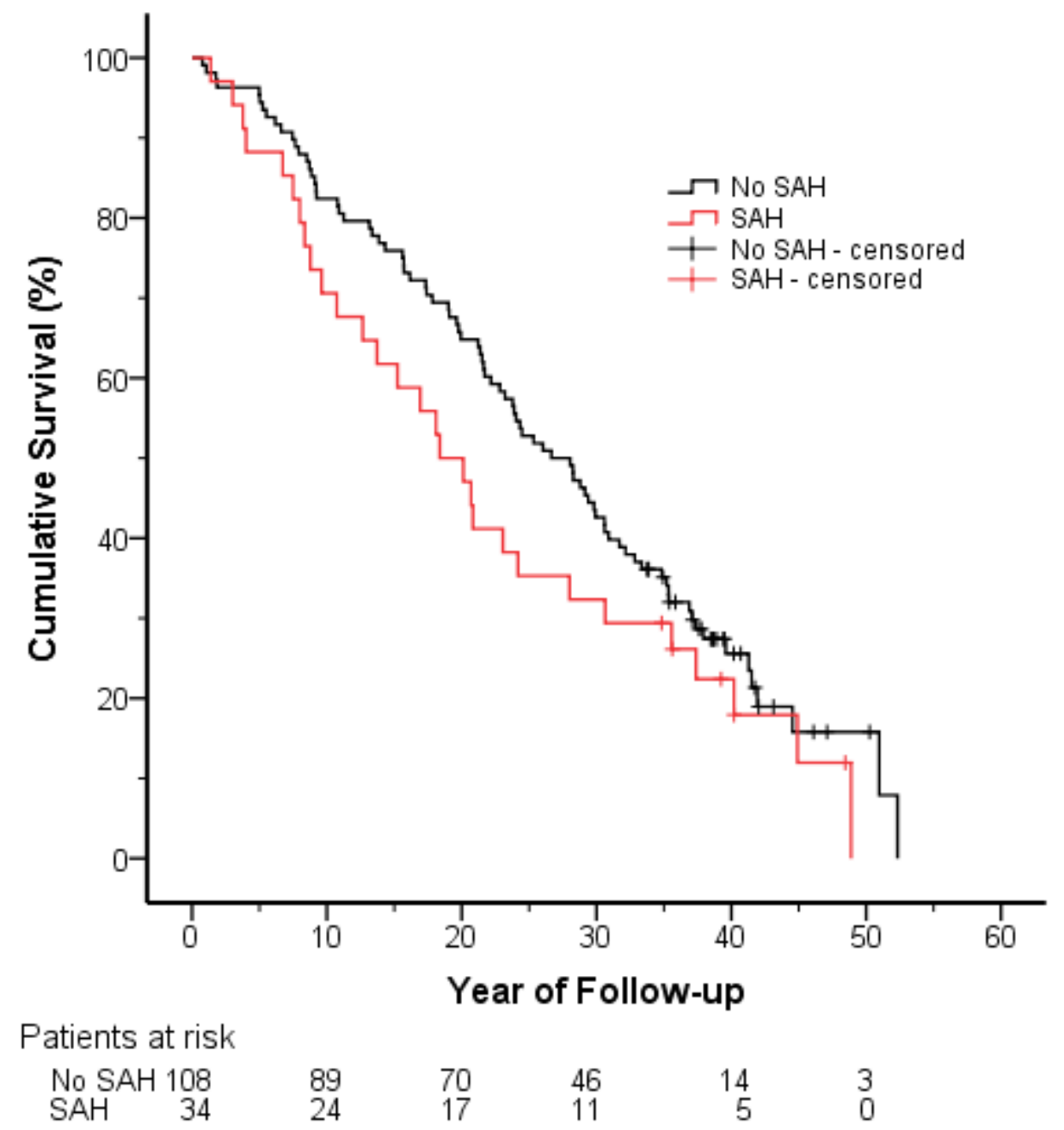

Those who had an aneurysm rupture (red line) had nonsignificantly shorter survival time than others (black line) (difference of median survival times of 8.3 years, 18.4 vs. 26.7 years, $p=0.154$ ). The markers of the curves indicate censored events. $\mathrm{SAH}=$ subarachnoid hemorrhage. 
Figure e-2. Cumulative survival curves of those with and without a later subarachnoid hemorrhage from diagnosed unruptured aneurysm according to age groups ( $<41$ years vs. vs. vs. $\geq 41$ years).

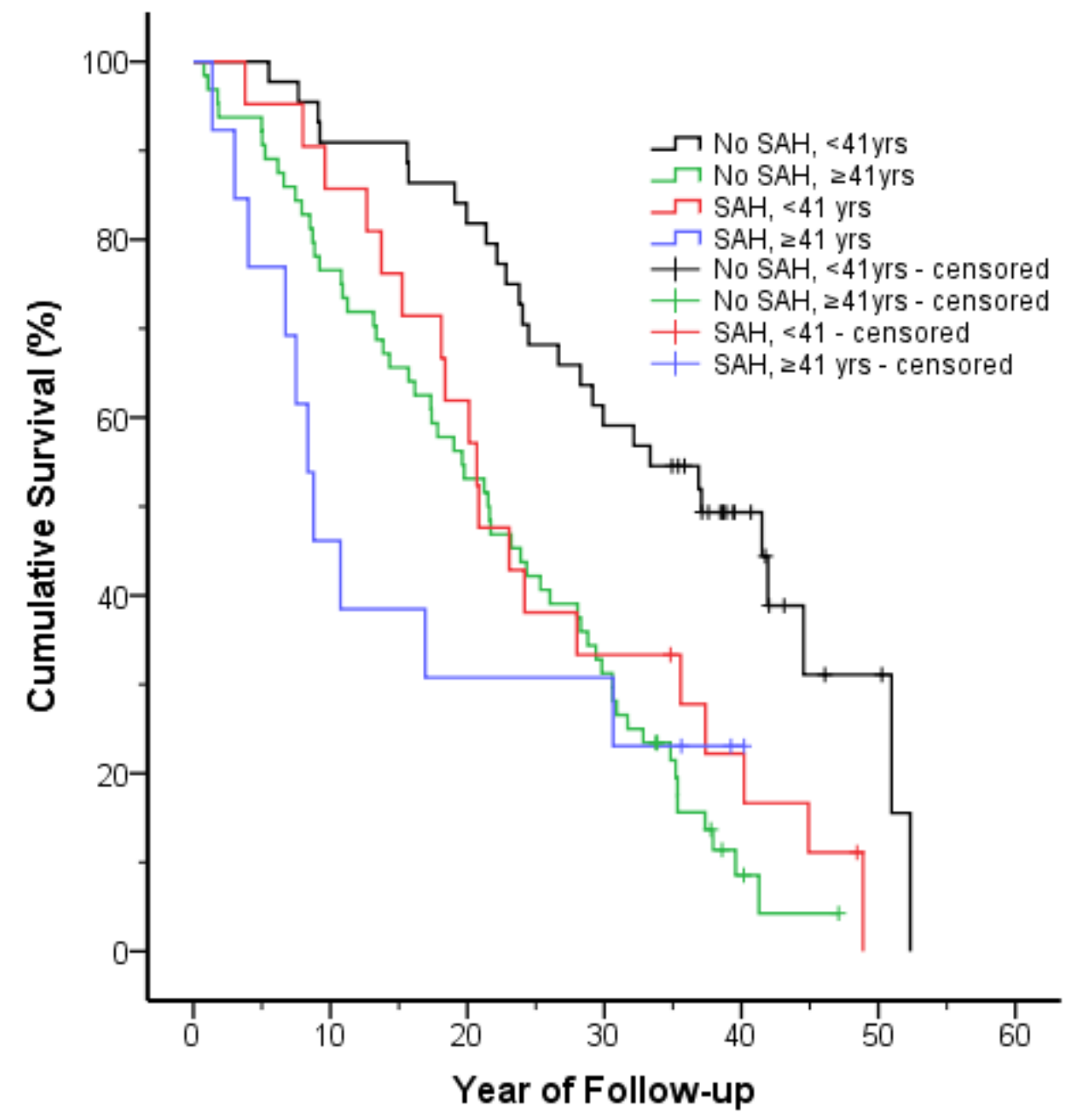

Those aged $<41$ years who had an aneurysm rupture (red line) had significantly shorter survival time than others aged $<41$ years (black line) (difference of median survival times of 16.3 years, 20.8 vs. 37.1 years, $p=0.008$ ) while among those aged $\geq 41$ years (green line for those without $\mathrm{SAH}$ and blue one for those with SAH), the difference was not significant (difference of median survival times of 12.8 years, 8.8 vs. 21.5 years, $\mathrm{p}=0.77$ ). The markers of the curves indicate censored events. $\mathrm{SAH}=$ subarachnoid hemorrhage. 
Figure e-3. Cumulative mortality in relation to sex.

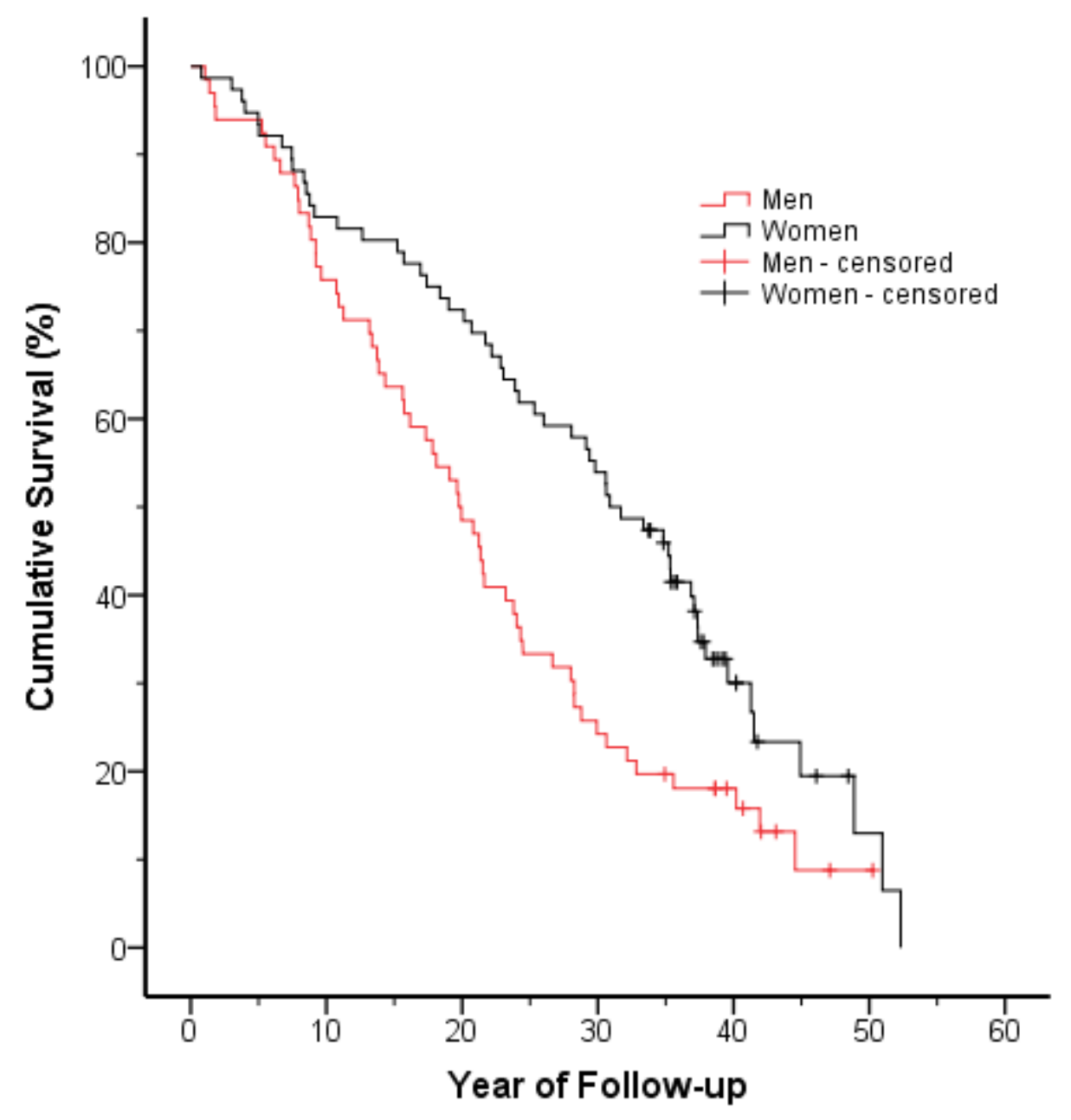

Kaplan-Meier curves showing cumulative mortality in relation to sex. Men (red line) had a shorter survival rate than women (black line)(difference of median survival times of 11.1 years, 19.8 vs. 30.9 years, $\mathrm{p}=0.004)$. The markers of the curves indicate censored events. 
Figure e-4. Cumulative survival in relation to cigarette smoking.

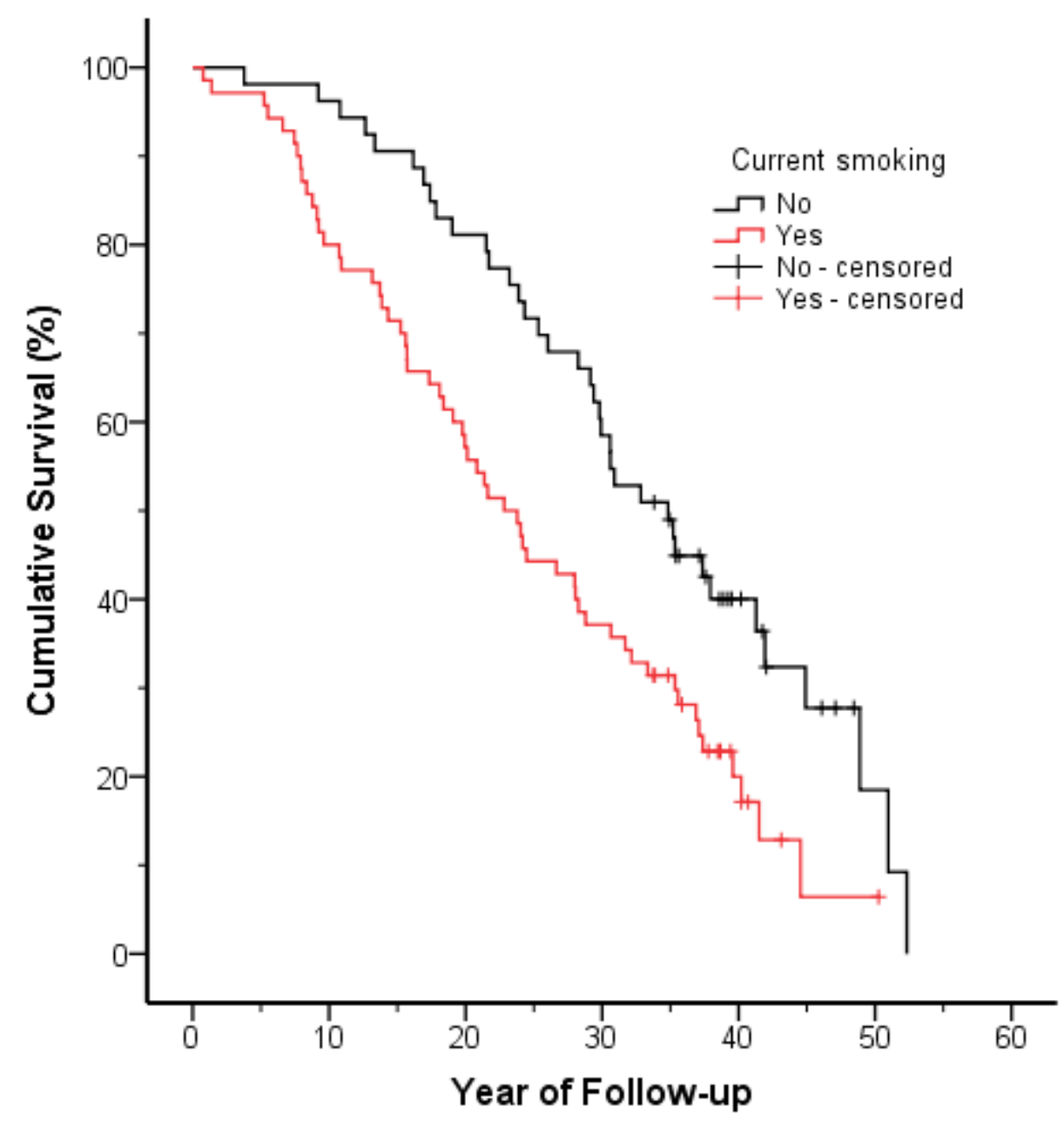

Kaplan-Meier curves showing cumulative mortality in relation to current cigarette smoking at the beginning of follow-up. Smokers (red line) had a shorter survival rate than nonsmokers (black line) (difference of median survival times of 12.0 years; 22.8 vs. 34.8 years, $p=0.003$ ). The markers of the curves indicate censored events. 
Figure e-5. Cumulative survival in relation to heavy alcohol consumption.

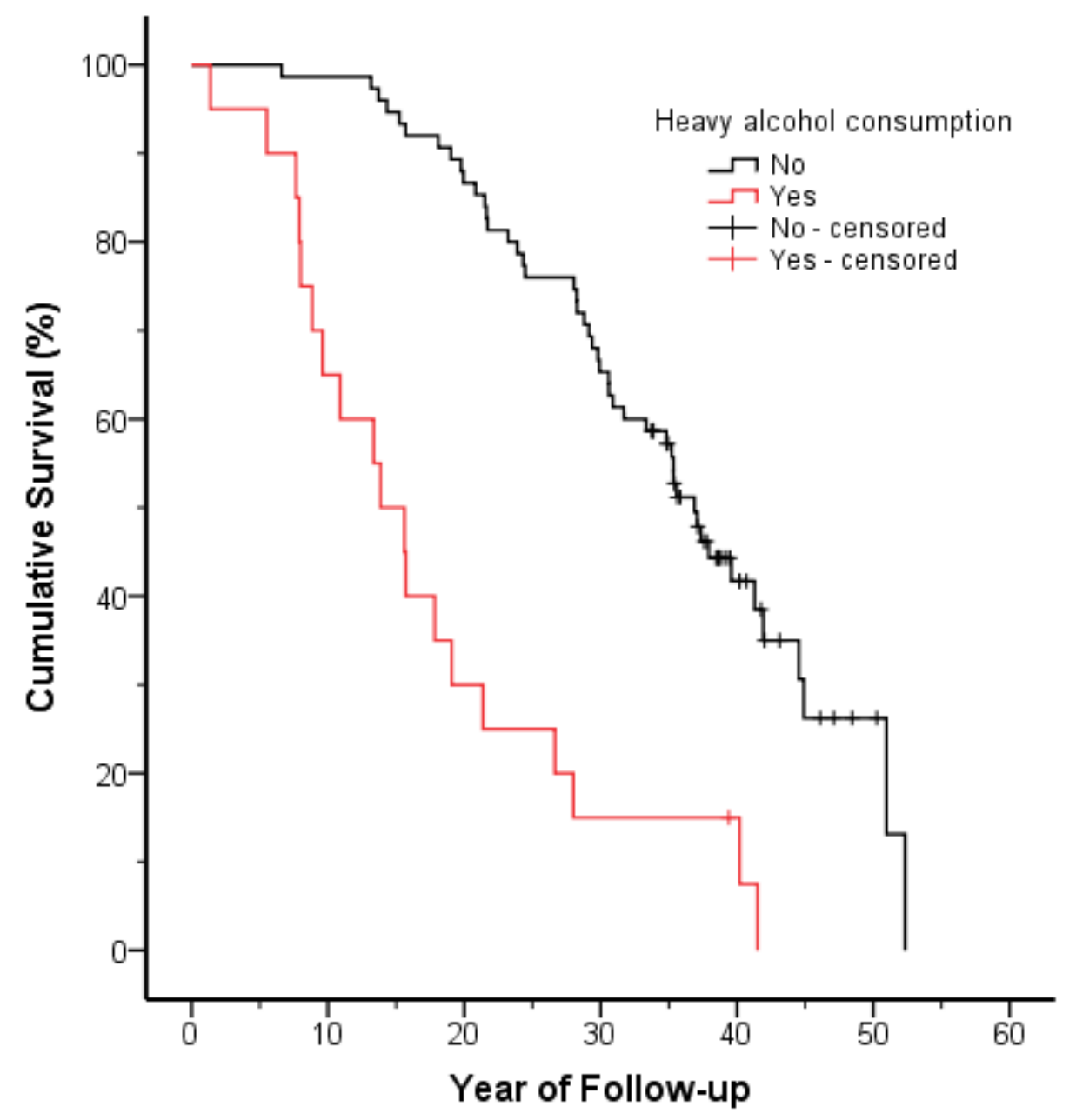

Kaplan-Meier curves showing cumulative mortality in relation to heavy alcohol consumption at the beginning of follow-up. Heavy drinkers (red line) had a shorter survival rate than others (black line) (difference of median survival times of 23.0 years; 13.9 vs. 36.9 years, $p<0.001$ ). The markers of the curves indicate censored events. 